\title{
Retalho de omento maior para indução de vascularização e consolidação óssea em cão
}

\author{
Use of omental flap to induce vascularization and bone healing in a dog
}

\author{
Cássio Ricardo Auada Ferrigno ${ }^{\mathrm{I}}$ Kelly Cristiane Ito $^{\mathrm{I}^{*}}$ Daniela Fabiana Izquierdo Caquias \\ Tatiana Casimiro Mariani ${ }^{I}$ Marcos Ishimoto Della Nina ${ }^{I}$ Vanessa Couto de Magalhães Ferraz \\ Olicies da Cunha ${ }^{I}$ Leandro Romano
}

\begin{abstract}
Este trabalho relata o caso de uma cadela da raça whippet, de 10 anos, com união retardada de tíbia e fíbula esquerdas, exposta, cotaminada e com grande perda de massa muscular e óssea e de pele causada por instabilidade óssea decorrente de duas intervenções cirúrgicas realizadas anteriormente. Foi realizado retalho de omento maior em camada simples, alcance ao foco de fratura via túnel subcutâneo e recobrimento por enxerto cutâneo em malha. $O$ objetivo do trabalho foi avaliar a capacidade de indução vascular do omento maior para foco de fratura $e$ consequentemente consolidação óssea, tendo como hipótese a acentuada função de angiogênese do omento maior. A tíbia e fíbula esquerdas foram estabilizadas com fixador circular externo. Após 80 dias, houve consolidação óssea da tíbia, volta do apoio do membro e retirada do implante.
\end{abstract}

Palavras-chave: omentalização, fratura exposta, fixador circular.

\section{ABSTRACT}

This research reports the case of a whippet female dog, 10 years old, with delayed union of left tibia and fibula, exposure of the fracture focus with localized infection, and extensive loss of, muscle, bone and skin after instability caused by two surgical interventions accomplished previously. A flap was made of the greater omentum in a single layer. The fracture site was reached through the subcutaneous tunnel and the coating by mesh skin grafts. The objective of this study was to evaluate the ability of the larger omentum to induce angiogenesis to the fracture site and the subsequent bone healing, considering the strong role of angiogenesis. The left tibia and fibula were stabilized with external circular fixator.

\begin{abstract}
After 80 days there was bone healing of the tibia around the support member and removal of the implant. Postoperative complications included partial necrosis of the cutaneous $(25 \%)$ flap and shortening of the tibia with consequent laxity ligament of the member.
\end{abstract}

Key words: omentalization, exposed fracture, circular fixator.

Desde o século XIX, o omento maior vem sendo utilizado em diversos procedimentos cirúrgicos (PLATELL et al., 2000). Enxertos omentais têm sido utilizados com frequência em cirurgias gastrointestinais, vasculares e reconstrutivas em humanos e animais. As novas técnicas para cirurgias reconstrutivas e vasculares em pacientes veterinários vem sendo desenvolvidas, e a aplicação cirúrgica do omento tem se tornado cada vez mais importante (HOSGOOD, 1990).

GOLDSMITH (1967) comprovou patência vascular do pedículo 30 dias após a tunelizacão. A partir desses achados, foi realizada tunelizacão subcutânea em pacientes humanos portadores de linfedema crônico para membro superior e inferior, sendo obtido retalho funcional após tunelização. GOLDSMITH (1973) descreveu a capacidade angiogênica de retalho de omento na superfície cerebral de cães, além de comprovar que a passagem através de túnel subcutâneo é possível sem efeitos deletérios ao pedículo.

\footnotetext{
'Departamento de Clínica Cirúrgica, Universidade de São Paulo (USP), São Paulo, SP, Brasil. E-mail: itokelly@yahoo.com.br. *Autor para correspondência.
} 
ROA et al. (1999) descreveram o primeiro relato de transplante de enxerto livre de omento para extremidades em cães por meio de técnica de microanastomose. Em trabalho experimental, ITO et al. (2008) concluíram que é possível alcançar a metáfise distal dos ossos longos fêmur, tíbia/fíbula, úmero e rádio/ulna de cães, a partir da extensão do omento maior em retalho em L, mantendo seu pedículo vascular. Frente à propriedade do omento maior em induzir a angiogenese a estruturas nas quais é aplicado e versatilidade de criação de retalho, o objetivo deste trabalho foi avaliar o alcance do retalho de omento maior para extremidades e sua capacidade de indução vascular para enxertos cutâneos de malha e em foco de fratura.

Cadela da raça whippet, de 10 anos, com união retardada de tíbia e fíbula esquerdas e exposição óssea da fratura associada à perda extensa de massa muscular e óssea e de pele, decorrente de duas intervenções cirúrgicas prévias sem sucesso, foi submetida à avaliação clínica e radiográfica, sendo escolhida a estabilização com fixador circular, retalho pediculado de omento maior e enxerto cutâneo em malha (FOSSUM et al., 2005), a fim de recobrir a exposição óssea no foco de fratura e o retalho de omento maior.

O procedimento cirúrgico foi realizado por duas equipes. Uma equipe realizou a confecção do retalho de omento em camada simples (Figura 1A). O omento maior foi desinserido da região do pâncreas mantendo a vascularização proveniente das artérias gastroepiploica direita e esplênica esquerda. O túnel até $\mathrm{o}$ acesso medial da tíbia esquerda foi realizado com aproximadamente $5 \mathrm{~cm}$ de largura e percorreu a região inguinal (Figura 1B) e medial do membro pélvico esquerdo (Figura 1C) até a linha de incisão da fratura (Figura 1D). A segunda equipe coletou fragmento ósseo para cultura e antibiograma, removeu tecido ósseo, musculatura e pele desvitalizados, levando a encurtamento de aproximadamente $2 \mathrm{~cm}$ do membro e iniciou a fixação da fratura com o fixador circular. Foram utilizados três anéis de oito centímetros, sendo um proximal e dois distais. Após fixação da fratura, o osso foi envolto com omento maior (Figura 1E). Simultaneamente à redução da fratura, a primeira equipe retirou retalho cutâneo de malha (FOSSUM et al., 2005) circular da região do flanco esquerdo com $10 \mathrm{~cm}$ de diâmetro. Foi realizado o preparo do retalho, e o enxerto foi posicionado sobre o omento na região da fratura (Figura 1F).

No pós-operatório, foi observada redução satisfatória (Figura 1G). Foi administrada cefalexina $30 \mathrm{mg} \mathrm{kg}^{-1}$ a cada 12 horas, nos primeiros sete dias pósoperatorios, a qual foi substituída por norfloxacina
$25 \mathrm{mg} \mathrm{kg}^{-1}$ a cada 12 horas, após o resultado da cultura e antibiograma, e manteve-se até o décimo dia a contar do último exame radiofráfico realizado com 80 dias de pós-operatório. Recebeu também carprofeno, dipirona sódica e cloridrato de tramadol. Curativos diários foram realizados inicialmente com solução salina $0,9 \%$ e nitrofurazona. Houve desvitalização de $25 \%$ do retalho cutâneo na região crânio-medial do membro, com sinais de necrose e evolução lenta durante a primeira semana. Os curativos continuaram sendo realizados com bandagem aderente com solução salina $0,9 \%$, até remoção do tecido desvitalizado e, após granulação, voltou-se ao protocolo inicial, e a ferida cicatrizou por segunda intenção. Foram realizadas radiografias de controle pós-operatórias a cada 20 dias e, após 80 , dias houve consolidação da fratura (Figura $1 \mathrm{H}$ ). Os implantes foram retirados (Figura 1I e 1J), e o paciente manteve o apoio com claudicação leve. Ao exame ortopédico, apresentava lacidez do tendão do gastrocnemio devido ao encurtamento da tíbia ocasionado pela perda de osso desvitalizado removido durante o procedimento cirúrgico. $\mathrm{O}$ omento do cão recebe a maioria do suprimento sanguíneo dos vasos da arcada gastroepiploica direita e da artéria splênica esquerda. Com base nessa arquitetura vascular, ROSS \& PARDO (1993) descreveram a primeira técnica de prolongamento do omento. A técnica utilizada neste caso foi a mesma descrita por ROSS \& PARDO (1993), pois, além da simplicidade do procedimento, ficou comprovada a manutenção da integridade vascular do pedículo. A tunelizacão de retalho de omento pediculado em humanos tem seu uso restrito, uma vez que DAS (1976) demonstrou, em trabalho com 200 cadáveres humanos, que é possível alcançar o tórax, os joelhos e os cotovelos com a extensão do omento, porém somente $15 \%$ alcançaram o tornozelo e $5 \%$ a extremidade distal do pé. O presente trabalho corrobora o estudo de ITO et al. (2010), os quais demonstraram que, em cães, essa restrição não existe provavelmente pela estrutura quadrupedal. No caso relatado, foi possível alcançar a diáfise da tíbia esquerda com retalho simples de omento maior.

O uso do omento para extremidades de membros tem várias vantagens. $\mathrm{O}$ omento é flexível e facilmente moldável, tem grande área de superfície e é capaz de fornecer pedículo vascular adequado. Tem excelente vascularização intrínsecca capaz de aumentar o fluxo sanguíneo de determinada região. Esse fluxo sanguíneo permite aumento local da tensão de oxigênio e fatores humorais que são importantes para combater infecções e acelerar cicatrização de tecidos. Segundo O'SHAUGHNESSY (2007), o aumento do fluxo sanguíneo também leva ao acúmulo de neutrófilos, 


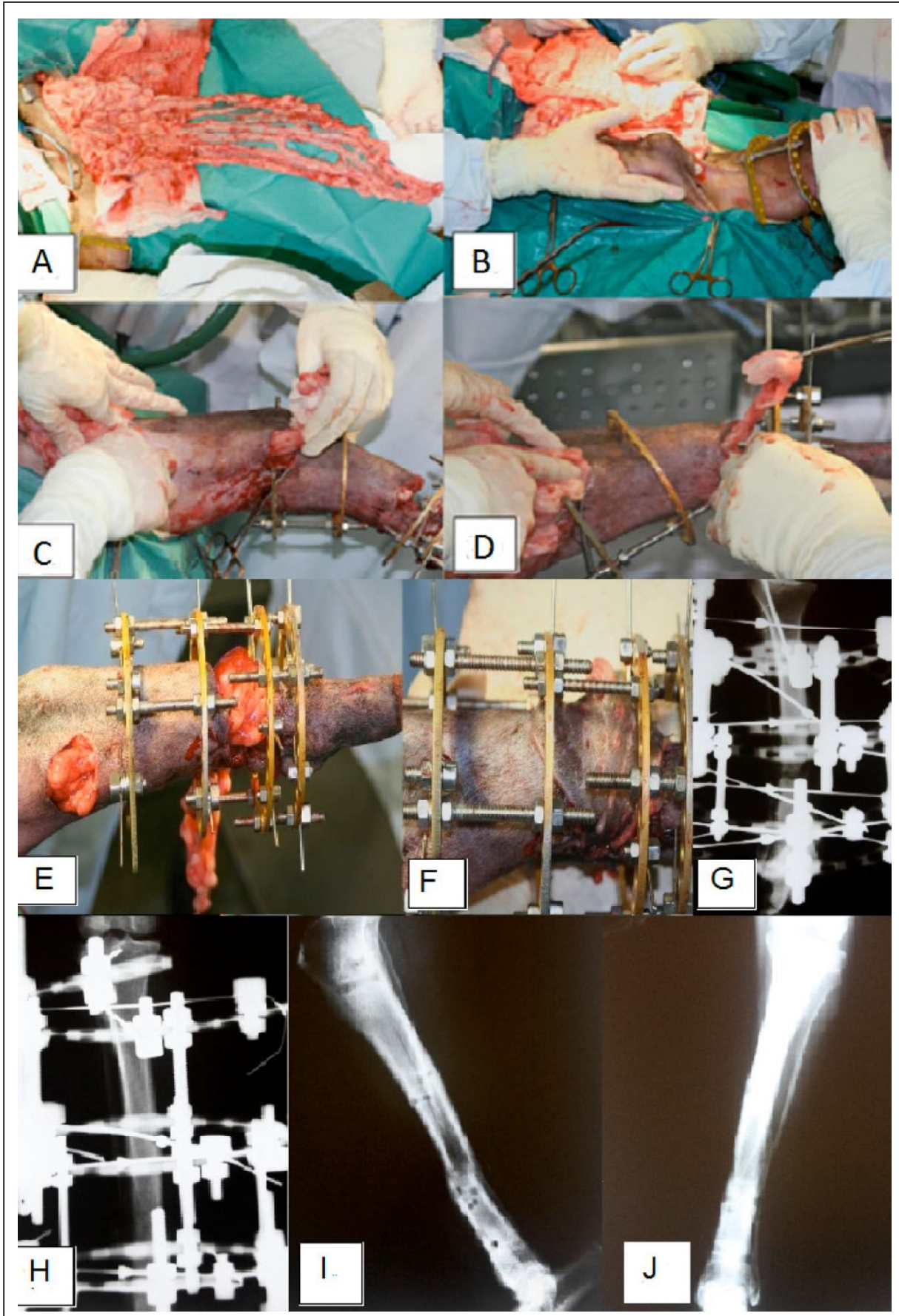

Figura 1 - (A) Retalho pediculado de omento maior em camada simples, estendido após desinserção dorsal do pâncreas e inserido na curvatura maior do estômago com vascularização principal preservada. (B) Trajeto do túnel subcutâneo do abdomem até e incisão de pele na região inguinal esquerda. (C) Passagem do retalho pediculado de omento através de túnel subcutâneo confeccionado a partir da região inguinal esquerda até incisão cutânea na região medial do joelho esquerdo. (D) Passagem do retalho pediculado de omento através do túnel subcutâneo a partir da região medial do joelho até o foco de fratura na tíbia esquerda. (E) Tíbia esquerda após redução com fixador circular e envolvimento do foco de fratura com retalho pediculado de omento maior após tunelização subcutânea. (F) Aspecto final pós-operatório da tíbia esquerda após redução com fixador circular, envolta com retalho pediculado de omento maior e retalho cutâneo em ilha. (G) Imagem radiográfica pós-operatória imediata com redução satisfatória da fratura. (H) Imagem radiográfica em projeção crânio-caudal da tíbia esquerda com 80 dias pós-operatórios, apresentando consolidação óssea da fratura. (I) Imagem radiográfica da tíbia esquerda em projeção lateral depois da retirada dos implantes demonstrando consolidação óssea com 80 dias pós-operatórios. (J) Imagem radiográfica da tíbia esquerda em projeção crânio-caudal depois da retirada dos implantes, demonstrando consolidação óssea com 80 dias pós-operatórios. 
macrófagos, fibroblastos e células endoteliais. A habilidade em induzir angiogenese aumenta a disponibilidade de antibióticos no sítio de infecção em casos de osteomielite, bem como promove cicatrização óssea. Acredita-se que o retalho pediculado de omento maior tenha contribuído para a contenção da infecção bacteriana causada pelo agente Proteus mirabilis.

Em 1990, Hosgood descreveu a utilização do omento maior em cirurgia veterinária baseada nas aplicabilidades da medicina, como na reconstrução da parede torácica e abdominal, na proteção de vasos e nos procedimentos reconstrutivos. Em 1993, ROSS \& PARDO descreveram a primeira técnica de prolongamento de omento maior no cão baseados na vascularização do omento e comprovaram a manutenção da viabilidade vascular do retalho. Assim, optou-se pelo uso do retalho pediculado de omento associado a enxerto livre de pele na tentativa de salvamento do membro, recobrindo e vascularizando extensa área de fratura exposta de tíbia, uma vez que ARNOLD, et al. (1976) realizaram com sucesso reconstrução de ferida crônica em tórax empregando omento associado a enxerto de pele. EROL \& SPIRA (1980) demonstraram também que é possível vascularizar enxerto de pele com vasos subjacentes proveniente de vascularização de enxerto pediculado de omento maior. O presente trabalho corroborou o estudo desses autores, confirmando ser possível a confecção do retalho pediculado de omento maior e manutenção de sua patência vascular para sítios distantes.

GOLDSMITH, em 1973, obteve sucesso com tunelização subcutânea de retalho de omento para superfície cerebral em cães e provou que um túnel subcutâneo pode ser possível sem efeitos deletérios ao pedículo. Com base nesse trabalho, optou-se pela tunelização do retalho de omento maior como nova fonte de vascularização para o osso e os tecidos adjacentes.

Após consolidação óssea, houve encurtamento do osso e achinelamento do membro. $\mathrm{O}$ planejamento inicial envolvia nova intervenção cirúrgica de osteotomia da tíbia e dinamização do osso para recuperar o comprimento e corrigir a lacidez ligamentar do membro. O proprietário optou por não realizar novo procedimento, pois estava satisfeito com o resultado.

A partir dos resultados obtidos, tratandose de cadela de 10 anos de idade com fratura complicada por perda extensa de tecidos e união óssea retardada, esperava-se evolução lenta de cicatrização óssea, em torno de 120 a 160 dias, entretanto houve consolidação em 80 dias. Conclui-se que o retalho de omento maior pediculado simples pode alcançar a diáfise tibial, corroborando ITO et al. (2010), que funciona como leito vascular para enxertos cutâneos de malha, e confirmando achados de EROL \& SPIRA (1980) e ARNOLD et al. (1976), ao acelerar o processo de cicatrização óssea devido a sua atividade angiogênica sobre estruturas adjacentes onde é aplicado.

\section{REFERÊNCIAS}

ARNOLD, G.P. et al. One stage reconstruction of the breast using the transposed greater omentum. Case report. Plastic and Reconstructive Surgery, v.57, p.520, 1976.

DAS, S.K. The size of the human omentum and methods of lengthening it for transplantation. British Journal of Plastic Surgery, n.39, p.170-174, 1976.

EROL, O.; SPIRA, M. Development and utilization of a composite island flap employing omentum: experimental investigation. Plastic and Reconstructive Surgery, v.65, n.4, p.405-418, 1980.

FOSSUM, T.W. et al. Cirurgia do sistema tegumentar. In: Cirurgia de pequenos animais. 2.ed. São Paulo: Rocca, 2005. p.187-188.

GOLDSMITH, H.S. et al. Relief chronic lymphedema by omental transposition. Annals of Surgery, v.166, n.4, p.573583, 1967. Disponível em: <http:www.ncbi.nih.gov/pmc/ articles/PMC1477440/pdf/annsurg00442-0065.pdf >. Acesso em: 17 dez. 2009.

GOLDSMITH, H.S. et al. Brain vascularization by intact omentum. Archives of Surgery, v.106, p.695-698, 1973.

HOSGOOD, G. The omentum - the forgotten organ: physiology and potential surgical applications in $\operatorname{dog} s$ and cats. Compendium on Continuing Education for the Practicing Veterinarian, v.12, n.1, p.45-50, 1990.

ITO, K. et al. Extensão máxima de retalho pediculado de omento maior através de túnel subcutâneo para ossos longos em cães. Ciencia Rural, v.40, n.3, p.594-599, 2010. Disponivel em: <http://www.scielo.br/scielo.php?script=sci_arttext\&pid=S0103$84782010000300015 \& \operatorname{lng}=e s \& n r m=i s o>$. Acesso em: 18 jul. 2010. doi: $10.1590 / \mathrm{S} 0103-84782010005000020$.

O'SHAUGHNESSY, B.A. et al. Pedicled omental flaps as an adjunct in the closure of complex spinal wounds. Spine, v.32, n.26, p.3074-3080, 2007.

PLATELL, C. et al. The omentum. World Journal of Gastroenterology, v.6, n.2, p.169-176, 2000. Disponível em: 〈http: //www.wjgnet.com/1007-9327/6/169.pdf〉. Acesso em: 17 dez. 2009.

ROA, D.M. et al. Microvascular transplantation of a free omental graft to the distal extremity in dogs. Veterinary Surgery, v.28, p.456-465, 1999.

ROSS, W.E.; PARDO, A.D. Evaluation of an omental pedicle extension technique in the dog. Veterinay Surgery, v.22, n.1, p.37-43, 1993. Disponível em: <http://bases.bireme.br/ cgi-bin/wxislind.exe/iah/online/? Isis Script=iah/ iah.xis \&nextAction $=\operatorname{lnk} \&$ base=MEDLINE_19661996\&exprSearch $=8488673 \&$ index Search $=U I \& l a n g=e>$. Acesso em: 18 jul. 2010. 